\title{
Assessing the energy efficiency practices in cities across the world
}

\author{
Manas Vijayan*, Akshay Patil, Vijay Kapse and Sarika Bahadure \\ Department of Architecture and Planning, Visvesvaraya National Institute of Technology, Nagpur 440 010, India
}

Urban areas consume nearly two-thirds of the global energy and are responsible for $70 \%$ of overall greenhouse gas emissions. This energy can be broadly classified into three categories, i.e. embodied, operational and transport. Energy-efficient urban planning is an attempt to reduce the use of non-renewable energy sources, without sacrificing the quality of service. The strategies formulated for addressing energy efficiency will be targeting one or more of the energy types mentioned above. The present study evaluates the energy efficiency strategies adopted by cities across the world which are cited as best practices by the International Energy Agency. One of the key observations from this study is that most strategies address operational energy, while few address transport energy. For the purpose of assessing the impacts of these strategies, technique for order of preference by similarity to ideal solution analysis was carried out which revealed an overall poor performance score for the case cities, with highest score for Stockholm and lowest for Austin. It is also evident from the study that there is a lack of detailed energy assessment of cities prior to formulation of energy efficiency strategies. This study demonstrates a framework that can be adopted for assessing urban energy efficiency strategies, and helps to identify the issues pertaining to current practices.

Keywords: Best practices, embodied, energy-efficient urban planning, greenhouse gases, operational and transport energy.

GLOBAL primary energy demand rose by $1.9 \%$ in 2017 , the largest annual increase since 2010 and well above the preceding years. A major share of this came from emerging economies in the developing countries, where demand increased by $2.7 \%$.

The prime consumers are cities which use about twothirds of the global energy and are responsible for $70 \%$ of global greenhouse gas (GHG) emissions. This energy share is projected to reach almost three-quarters by 2030 due to continued urbanization in the developing countries of Asia and Africa ${ }^{1}$. The need for energy-efficient cities is therefore crucial now more than ever to make them sustainable. Energy efficiency in urban planning has been practiced since the last few decades. It is recognized in

\footnotetext{
*For correspondence. (e-mail: manas@students.vnit.ac.in)
}

the United Nations Sustainable Development Goals (SDGs) as 'Affordable and Clean Energy' and 'Sustainable Cities and Society' (SDG 11), to transform the world by 2030 (ref. 2).

Urban energy efficiency is crucial for a sustainable and healthy future as its impact includes, reducing energy use, GHG emissions and costs incurred; and associated environmental, social and health benefits due to reduced emissions. The World Bank identifies energy-efficient cities as a crucial tool to lower energy costs and GHG emissions; to build climate resilience and potentially yielding local co-benefits of job creation and improved air quality ${ }^{3}$.

A number of global agencies and organizations help cities in different countries to set energy targets for a more sustainable future. The strategies will vary from one city to another according to the set of conditions in which they exist, which includes factors like physical and geographical conditions, affordability and willingness to pay, availability of resources and the governance structure. Therefore, assessing and understanding the role of these varied factors on energy consumption is essential to formulate relevant strategies and for setting realistic targets.

Researches have been carried out to study energy consumption of cities based on cross-sectorial and individual parameters such as transport patterns, urban form, density and land-use mix. For example, Banister et $a l .{ }^{4}$ studied the relationships between energy use in transport and physical characteristics of a city, such as density, size and amount of open spaces. Gilbert and Dajani ${ }^{5}$ identified the role of transportation as a land-use development control, and the use of 'transportation performance standards' was proposed as a method for integrating transportation energy considerations into land development controls and decisions. Long et al. ${ }^{6}$ studied the impact of urban form, namely land-use pattern, distribution of development density, and the number and distribution of job centre, on residential commuting energy consumption. The life-cycle energy and environmental impacts due to different alterations of urban form indicators like land-use mix, building construction and vehicle ownership were assessed by Kimball et al. $^{7}$. The relationships between transportation energy consumption and urban form indicators, namely city population size, density and centre distribution pattern were studied for small and medium-sized cities in Korea ${ }^{8}$. 
The outcomes of such studies have contributed to 'transit-oriented development' and 'high-density development' in cities. It is safe to say that the past studies on energy consumption in cities have focused to a great extent on energy consumed in the transport sector.

While the relationships between transport energy consumption and land use, demography, density and other parameters have been studied by numerous researchers, only a few have assessed other forms of energy consumed by cities. These include energy consumed in the construction of structures, for providing various services and energy harnessed from renewable energy sources. For instance, Nichols and Kockelman ${ }^{9}$ combined daily operational and embodied energy demands to estimate lifecycle energy demands for residents and workers in different city settings. K1lkış ${ }^{10}$ used sustainable development of energy, water and environment systems (SDEWES) index for benchmarking city performance based on seven dimensions and 35 main indicators in 18 cities for comparison and diffusion of more sustainable practices for urban systems.

The inclination of these studies towards transport energy could be due to the fact that issues of this sector are encountered more in daily life than the rest. Nonetheless, it is worth determining the critical energy consuming sectors in urban areas.

Figure 1 shows the global energy consumption based on end-use ${ }^{11}$. The end-uses are classified into residential, transport, industries and services. It is evident from Figure 1 that the major energy-consuming sectors are transport and industries consuming 36\% and 30\% respectively, followed by residential (20\%) and services (14\%). For the purpose of comparison and greater insight, energy consumption in urban areas was also studied. Figure 2 shows the end-use energy consumption in urban areas ${ }^{12}$. The end-uses are classified into buildings, transport and others.

In urban areas, buildings consume $51 \%$ of the total supplied energy, transport $43 \%$ and others $6 \%$. It is evident from Figure 2 that the most critical energy-consuming

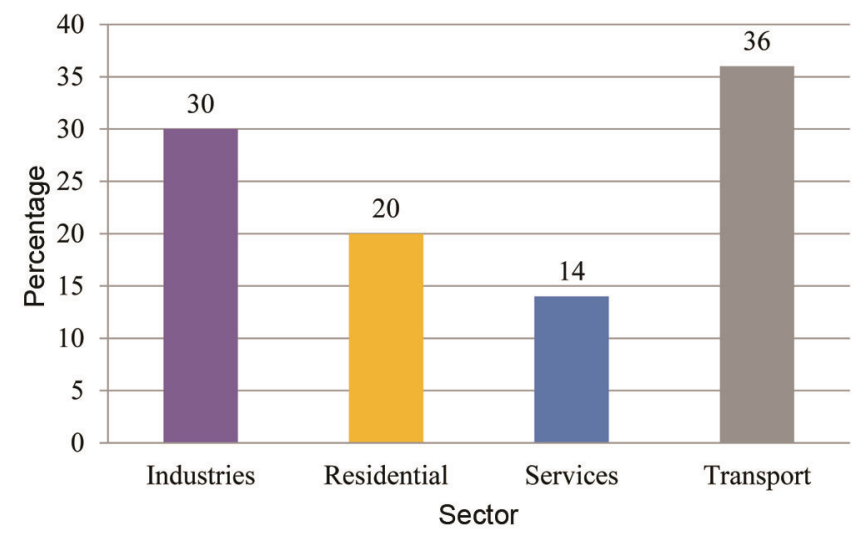

Figure 1. Global energy consumption. sector at the global level is transport and at the urban level it is buildings.

The outcomes and findings of peer-reviewed research such as the ones mentioned above are being adopted by urban area municipalities for formulating energy efficiency strategies. The bulk of such strategies is proposed targeting a particular service provided to the city like water supply ${ }^{13}$, wastewater treatment ${ }^{14}$, electricity from renewable sources ${ }^{15}$ and others. Since the strategies target a particular service in a city, study of different types of energy consumed for providing various services in the city is essential.

\section{Types of energy consumed in cities}

It is clear from the above discussions that cities consume energy of disparate types and forms. Various global organizations working on the energy sector have classified urban energy consumption in discrete ways. For instance, the UN Habitat Global Urban Observatory (GUO) classifies urban energy into transport, industrial and commercial activities, buildings and infrastructure, water distribution and food production based on endusers. The International Energy Agency (IEA) classifies it into residential, industrial, transport, services and other industries based on end-users. The World Research Institute (WRI) classifies it as renewable and non-renewable according to the type of fuel used. The Energy Sector Management Assistance Programme (ESMAP), a World Bank-initiated assistance programme, classifies energy consumed in cities as industry, transport, buildings and municipal services for various projects.

Researchers have classified energy based on the services that are consumed by a city, as embodied, operational and transport energy. For example, Nichols and Kockelman ${ }^{9}$ classified energy into operational and embodied to calculate life-cycle energy demands ${ }^{9}$. Troy et al. ${ }^{16}$ estimated the embodied and operational energy consumption of a city and suggested how it may be used as a development control tool in the planning system. Doherty et $a l .{ }^{17}$ examined the underlying interactions and relationships between the built environment, its spatial configuration

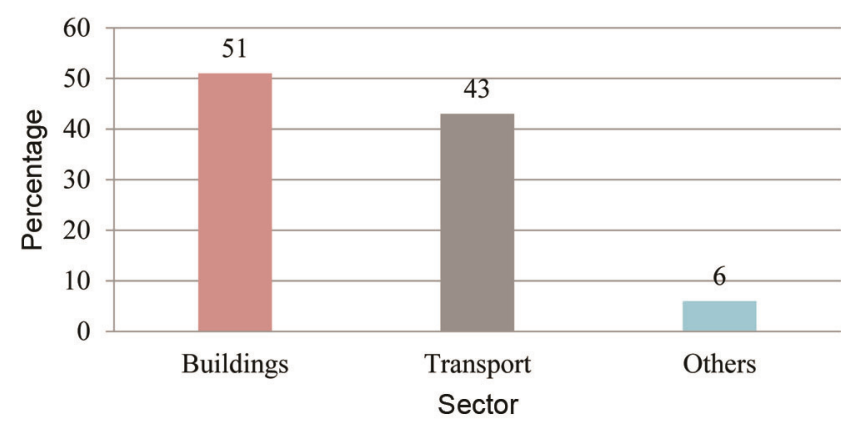

Figure 2. Energy consumption in urban areas. 


\section{RESEARCH ARTICLES}

and energy consumption, within and between residential land-use types by categorizing energy consumed into embodied, operational and transport ${ }^{17}$.

Categorizing energy consumed based on the services consumed by a city will enable researchers to understand it on an everyday basis. For example, the variance in energy consumed for providing indoor comfort in the summer and winter seasons is better understood when we study it based on the electricity consumed. Assessing strategies framed by cities for addressing energy is more comprehensible when focusing on the services that are targeted. Assessment of current trends in energy-efficient urban planning is crucial to identify the scope, limitations, constraints and opportunities associated with it.

\section{Need identification}

Even though energy-efficient urban planning has been practised for a long time now, how to address specific aspects of each type of energy, for a given set of conditions needs further analysis. A good understanding about various opportunities, probable constraints and how priorities should be set for a given local capacity, as well as geographical conditions and resources available is imperative to set targets for the future.

The purpose of the present study is to assess the energy efficiency strategies adopted by cities that are cited as best practices by the IEA report of 2008 (ref. 18); based on their target energy type, impacts achieved and process adopted for formulating strategies. The study will answer the following research questions. (i) Are the strategies adopted by cities addressing the most critical types of energy (embodied, operational and transport energy)? (ii) What are the beneficial impacts achieved through energy efficiency strategies adopted by cities? Are these beneficial impacts achieved by case cities justifiable? (iii) To what degree is the process adopted for framing energy efficiency strategies contributing towards the beneficial impacts achieved?

The study will enable planners and other stakeholders to understand the potentials and weaknesses in the current

Table 1. Case cities selected for the study

\begin{tabular}{ll}
\hline City & Country \\
\hline Adelaide & Australia \\
Sydney & Australia \\
Graz & Australia \\
Austin & USA \\
Berkeley & USA \\
Berlin & Germany \\
Riga & Latvia \\
Stockholm & Sweden \\
Christchurch & New Zealand \\
Dunedin & New Zealand \\
Gwalior & India \\
\hline
\end{tabular}

energy practices in cities. The framework used will assist researchers in assessing energy practices of various cities.

\section{Research methodology}

The methodology is divided into four stages. The first stage explains categorization of energy consumed in cities; the second stage describes how parameters were identified through literature review; the third stage describes the assessment tool and the fourth stage presents case study data.

\section{Case study}

The case-study cities have been selected as best practices of energy efficiency strategies as mentioned in the IEA report of 2008 (ref. 18). All the cities mentioned in this report have been considered regardless of their location, economic profile or climatic conditions. Table 1 lists 11 cities selected for this study.

First stage: Classification of energy - In view of the better perception achieved through categorizing energy consumed based on the services acquired by a city, this study categorizes energy consumed by cities into embodied, operational and transport energy.

The quantum of embodied energy in a city is to a great extent determined by the construction sector in urban areas; operational energy by the physical infrastructure, their functioning and the mechanisms used, and transport energy by the connection between points of residence, work and amenities, and mode of transport. The fuels used in these types will vary profoundly according to the location, geography, availability of resources, technology, climate and income of residents.

Embodied energy is the amount of energy required to extract, process and transport a material to the point of use or application ${ }^{19}$. It constitutes $10-20 \%$ of the total life-cycle energy of any product ${ }^{9}$. The major component of embodied energy in an urban area is the construction industry, which largely consists of buildings, roads and other infrastructure. The materials used, place of manufacture; method of construction and life span are some of the major factors which determine the quantum of embodied energy.

Operational energy is the energy consumed for the provision of various services like power supply, water supply and sewerage system in a city ${ }^{16}$. The energy consumed in each of these services depends on the type of system used, kind of fuel used, geography and location of the area, and availability of alternate sources. For example, a water-supply system working on gravity is less energy-intensive than the one using a pumping system. Similarly, a power-supply system which uses coal-fired 
RESEARCH ARTICLES

Table 2. Assessment tools used for assessing energy efficiency strategies

\begin{tabular}{|c|c|c|c|c|c|c|}
\hline \multirow[b]{2}{*}{ Assessment tool } & \multicolumn{6}{|c|}{ Parameters used } \\
\hline & $\begin{array}{l}\text { Energy } \\
\text { savings }\end{array}$ & $\begin{array}{l}\text { Emission } \\
\text { reduction }\end{array}$ & $\begin{array}{c}\text { Cost } \\
\text { savings }\end{array}$ & $\begin{array}{c}\text { Market } \\
\text { transformation }\end{array}$ & Co-benefits & Others \\
\hline California evaluation framework & 1 & 1 & 1 & 1 & 1 & 2 \\
\hline EMEEES & 1 & 0 & 1 & 0 & 0 & 0 \\
\hline ESMAP & 1 & 1 & 2 & 0 & 0 & 1 \\
\hline National Energy Efficiency EMV & 1 & 1 & 0 & 1 & 1 & 2 \\
\hline National Action Plan for Energy Efficiency & 2 & 1 & 1 & 0 & 1 & 0 \\
\hline NYSERDA & 2 & 0 & 1 & 1 & 0 & 1 \\
\hline ACEEE & 1 & 0 & 0 & 0 & 0 & 4 \\
\hline RCREEE & 1 & 1 & 2 & 1 & 0 & 3 \\
\hline LEAP & 2 & 1 & 1 & 0 & 0 & 1 \\
\hline MARKAL & 1 & 1 & 2 & 0 & 0 & 2 \\
\hline TIMES & 0 & 2 & 1 & 0 & 0 & 4 \\
\hline KAPSARC & 2 & 0 & 1 & 0 & 1 & 0 \\
\hline OSeMOSYS & 1 & 1 & 0 & 0 & 1 & 6 \\
\hline Energy PATHWAYS & 1 & 1 & 1 & 0 & 0 & 1 \\
\hline ETEM & 1 & 1 & 0 & 0 & 0 & 1 \\
\hline MESSAGE & 1 & 1 & 1 & 0 & 1 & 3 \\
\hline SDEWES & 1 & 1 & 0 & 0 & 4 & 1 \\
\hline Total & 20 & 14 & 15 & 4 & 9 & 32 \\
\hline Percentage & 21 & 15 & 16 & 4 & 10 & 34 \\
\hline No. of tools using a given parameter (out of total 17) & 16 & 13 & 12 & 4 & 6 & 13 \\
\hline
\end{tabular}

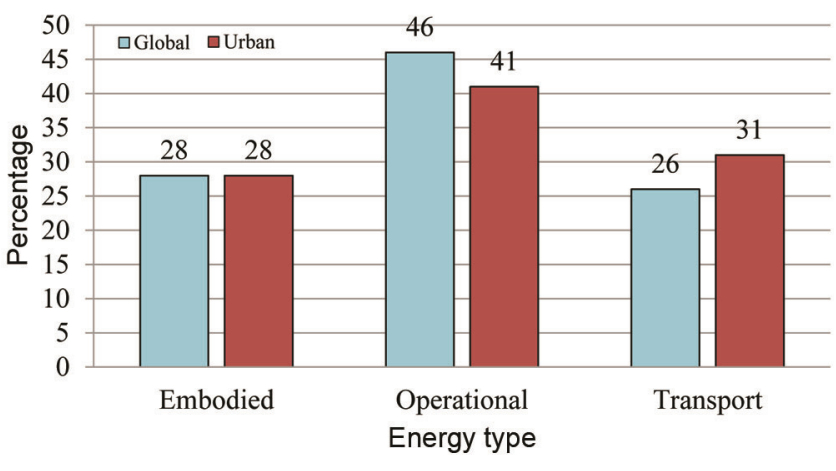

Figure 3. Percentage distribution of energy types at the level and in urban areas.

technology is more energy-intensive than a hydroelectric system.

Transport energy is the energy incurred in transportation of people, goods and services. The energy consumed depends on the connectivity between place of work, stay, other social and environmental amenities; mode of transport, fuel used and availability of public transport.

The amount of energy consumed for each of these services is determined by various factors. Cities which have adopted global and national initiatives, implemented policies, rules and regulations for the use of green and renewable materials for construction will have total embodied energy lower than other cities. The extent to which the built environment adapts to local climatic conditions affects the power-supply demands. Cities with higher density tend to have lower per capita infrastructure length, indicating potentially smaller life-cycle cost per capita and hence more energy-efficient services ${ }^{20}$. The spatial dimension of urban areas, coordination of resident and job densities, accessibility of jobs, services; and amenities by walking, cycling, and public transportation directly affect the consumption of transport energy. Highdensity urban areas tend to have lower transport energy consumption due to reduced travel distance.

Understanding the critical energy types at the urban and global levels is significant before assessing energy efficiency strategies adopted by the cities.

The end-use energy consumption data given in Figures 1 and 2 were normalized to calculate the percentage distribution of embodied, operational and transport energy consumption at the urban and global levels (Figure 3). The percentage distribution was calculated considering embodied energy to be taking $15 \%$ of the total energy consumed $^{9}$ and furthermore $15 \%$ in individual energy types.

Figure 3 manifests the criticality of operational energy at both global level (46\%) and urban level (41\%). It will be essential to study whether the formulated energy efficiency strategies in case cities can address the critical energy types mentioned in Figure 3; and what are the impacts of these strategies.

To assess strategies based on the impacts achieved, a set of parameters needs to be identified which will reveal the corresponding results.

Second stage: Selection of parameters-Parameters were identified by studying various assessment tools used for evaluating energy efficiency strategies in cities, by different agencies and organizations across the world. 


\section{RESEARCH ARTICLES}

The programme used for assessing strategies in a proposal is typically called measurement and verification $(\mathrm{M} \& \mathrm{~V})$. This is a critical aspect of any energy efficiency project for various functions, such as to assess projects and ensure value for money, justify continued or increased funding, examine the impacts achieved as well as to provide the basis of performance-based payment mechanisms $^{21}$. Seventeen assessment tools used across the world were evaluated to identify the parameters (Table 2).

Each tool uses different parameters for assessing the performance of energy efficiency strategies. Table 2 shows the parameters used by each tool for assessing strategies, percentage distribution of total number of parameters, and the number of assessment tools of the total 17 which use each of the parameters.

Among all the parameters used in the assessment tools, $21 \%$ were on energy savings, $15 \%$ on emissions reductions, $16 \%$ on cost savings, $10 \%$ on co-benefits, $4 \%$ on market transformation and 34\% for all remaining parameters (Table 2).

Among the 17 assessment tools studied, 16 had energy savings, 12 had cost savings and 13 had emissions reduction as a parameter for assessing strategies. 'Co-benefits' was used as a parameter by six tools. The data highlight the significance given for energy savings, emission reduction and cost savings in the assessment tools.

Assessment of strategies using multiple parameters will require a method with which it can be done satisfactorily.

Third stage: Assessment tool-For assessing the impacts achieved through energy efficiency strategies, multi-criteria decision-making (MCDM) method was adopted using technique for order of preference by similarity to ideal solution (TOPSIS) tool. This tool allows a researcher to assign relative weights to each parameter and develop multiple scenarios.

TOPSIS was originally developed by Ching-Lai Hwang and Yoon in 1981 with further developments by Yoon in 1987, and Hwang, Lai and Liu in 1993. It is based on the idea that the chosen alternative should have the shortest distance from the positive ideal solution and, on the other hand, the farthest distance from the negative ideal solution $^{22}$. Weights of different parameters are to be assigned by the researcher.

The parameters chosen in the present study to assess the impacts achieved through energy efficiency strategies were energy savings, cost savings and emissions reduction. All three parameters are direct quantifiable data provided by the M\&V organizations of cities. The para-

Table 3. Selected parameters and assigned weights

\begin{tabular}{lc}
\hline Parameter & Weight (\%) \\
\hline Direct energy savings & 0.33 \\
Greenhouse gas (GHG) emission reduction & 0.33 \\
Investment returns & 0.33 \\
\hline
\end{tabular}

meters were selected based on literature review done on $\mathrm{M} \& \mathrm{~V}$ tools. Table 3 shows the final parameters and their respective weights.

In this study all three parameters mentioned in Table 3 were given equal weights of 0.33 (out of total 1.00) for analysis. The method used for assigning weights to parameters involves either a detailed context study of the study area, or an expert opinion survey followed by a matrix analysis through analytical hierarchy process (AHP) or analytical network process (ANP). Neither of the methods was suitable for the present study as the case-study cities belong to different climate, location and economic profiles; and were not selected based on these criteria. Findings from an expert opinion survey will also be inconclusive and subjective for the same reason. The parameters were hence assigned equal weights in the analysis. The normalization of impacts achieved in energy savings $(\mathrm{kWh}), \mathrm{GHG}$ emissions reduction $\left(\mathrm{CO}_{2}\right.$ eq) and cost returns (US\$) was done by converting the values into percentage (savings/reduction/returns).

The equations used for calculating Euclidean distance from ideal positive and ideal negative solutions using the selected parameters are mentioned below.

Distance from ideal positive

$$
S_{i+}=\left[\sum_{j=1}^{m}\left(V_{i j}-V_{j+}\right)^{2}\right]^{0.5} .
$$

Distance from ideal negative

$$
S_{i-}=\left[\sum_{j=1}^{m}\left(V_{i j}-V_{j-}\right)^{2}\right]^{0.5},
$$

where $S_{i+}$ and $S_{i-}$ are the Euclidean distance from ideal positive and ideal negative value respectively for case city $i, V_{\mathrm{ij}}$ the weighted normalized value of case city $i$ in parameter $j, V_{j+}$ and $V_{j-}$ the maximum and minimum values respectively in weighted normalized decision matrix for parameter $j$ and $m$ represents the number of cities assessed in the study.

A greater Euclidean distance from ideal positive compared to other case cities indicates poor performance, and a greater distance from ideal negative indicates good performance and vice versa. These two values were used to calculate the performance score for each city.

The equation used for calculating performance score of each city is

$$
P i=\frac{S_{i-}}{S_{i+}+S_{i-}},
$$

where $P_{i}$ is the performance score of case city $i$, and $S_{i+}$ and $S_{i-}$ are the Euclidean distance from ideal positive and ideal negative value respectively, for case city $i$. 
The performance score values of a city can vary from 0 to 1 , with 0 being the lowest score indicating very poor performance and 1 being the highest score indicating the best performance.

\section{Strategy formulation}

Prior to assessing the strategies based on impacts achieved and target energy type, it is essential to study the process involved in their formulation. Strategies adopted in a city are studied as an end-result of a process, where the first step is the awareness/consciousness about an issue in hand; second, the approach adopted by the subject to address the issue; third, strategy formulated to execute the approach adopted, and fourth, the final schemes used with respect to the strategy formulated. A study of different types of awareness generated in a subject, and types of approaches adopted towards an issue is necessary to assess the process involved in the formulation of strategies.

The awareness or consciousness towards an issue is classified as introspective, self and inferential. Introspective awareness is the awareness of an issue generated through a higher body and also through self-consciousness towards which the subject acts upon. Self-awareness is generated by oneself when the issues are identified by observation and assessment of various indicators, which one understands and acts upon ${ }^{23}$. Inferential awareness is a minor scale of self-awareness, where an issue is considered as an independent event and happens at a specific place. Issues identified through inferential awareness are often not projected at a national or global scale ${ }^{24}$.

The approach towards solving an issue can be analytical, rational, logical, absolute, creative or positive type. An analytical thinker has the ability to get into the details of a problem, evaluate all components, indicators and develop perspectives to understand it and determine what is missing ${ }^{25}$. A rational problem-solver takes information that is available and makes assumptions based on it; deducting the most optimal solution given his personal perspective. Such a decision-maker will not be able to address the problems faced by a community as a whole as he is blind-sided towards some of them. A logical thinker has the ability to continuously collect details of an event, put it into sequence, allowing him to see the bigger picture, evaluate where the problem exists and why. He can infer solutions based on similar situations using historical examples. An absolute problem-solver has the ability to see a problem as black or white, and a solution as right or wrong. He tries to find that solution by seeking an authoritative source that can confirm the answer. A creative problem-solver has the ability to envision several outcomes, make assumptions as to what needs to be done to achieve an outcome and is willing to take risks because he has confidence in his own judgement. A positive problem-solver has the ability to compartmentalize a problem as an individual event and seek solutions with an open mind. The limitation of positive thinkers is that the problems recur several times before solutions are put in place, because they are not pragmatic enough to solve the issues $^{26}$.

Strategies formulated by a city will be preceded by a specific type of awareness and approach. For instance, a city adopting global agenda of 'zero carbon emissions' possesses introspective awareness towards an issue; while a city addressing depleting groundwater level in the region possesses inferential or self-awareness. Similarly, a city constructing an overpass bridge to reduce traffic congestion is adopting a logical/absolute approach, while an analytical or rational problem-solver may try to address the root cause of traffic congestion by changing working hours, controlling freight traffic movement, etc.

Fourth stage: Data presentation - To assess the process behind formulation of strategies in the case cities, Table 4 shows the type of awareness generated towards the issue each city faced, and the approach adopted and strategies formulated to address them.

Table 4 shows that four of the case cities had introspective awareness towards the issue, two had selfawareness, one had inferential awareness, and one had a combination of introspective and self-awareness. Eight of the 11 case cities adopted a rational approach towards the issue, two adopted an absolute approach and one city adopted an analytical approach.

In theory, a city which has self-awareness about the issue and chooses an analytical approach towards addressing it should have a better performance compared to other cities. To evaluate the performance of each city, the impacts achieved with respect to energy savings, emission reduction and cost returns were assessed using TOPSIS analysis. Table 5 shows the impacts achieved through a specific strategy and the performance score generated through TOPSIS analysis for the 11 case cities.

\section{Analysis}

\section{TOPSIS analysis: performance score}

Figure 4 shows the Euclidean distance from ideal positive and ideal negative for the 11 case cities, and the combined average distance from ideal positive and ideal negative.

Figure 4 shows that the average distance from ideal positive is 26.00 and from ideal negative is 14.84 . The numbers indicate a poor performance for the case cities as the distance from ideal positive should be less than the distance from ideal negative. Stockholm has the best performance with distance from ideal positive at 5.00 and from ideal negative at 35.11. Austin shows the worst 
RESEARCH ARTICLES

Table 4. Cities, types of awareness, approaches and strategies formulated to tackle the issue

\begin{tabular}{|c|c|c|c|}
\hline City & Awareness & Approach & Strategy \\
\hline Adelaide $^{39}$ & $\begin{array}{l}\text { Inferential: high carbon emissions and } \\
\text { costs of public lighting }\end{array}$ & $\begin{array}{l}\text { Rational: reducing with technologically } \\
\text { advanced, high-efficient fixtures }\end{array}$ & $\begin{array}{l}\text { Replacing high energy-consuming lights } \\
\text { with energy-efficient ones }\end{array}$ \\
\hline Sydney ${ }^{40}$ & $\begin{array}{l}\text { Introspective: Energy Efficiency in } \\
\text { Government Operation (EEGO) } \\
\text { policy }\end{array}$ & $\begin{array}{l}\text { Rational: improving energy efficiency of } \\
\text { Australian Government operations }\end{array}$ & $\begin{array}{l}\text { Introduction of retrofitting policies, and } \\
\text { implementation strategies. Improving } \\
\text { the energy and water efficiency in } \\
\text { public buildings }\end{array}$ \\
\hline $\mathrm{Graz}^{41}$ & - & $\begin{array}{l}\text { Rational: 'Thermoprofit' scheme to } \\
\text { increase energy efficiency }\end{array}$ & $\begin{array}{l}\text { Replacing old luminaires and lamps by } \\
\text { highly-efficient units }\end{array}$ \\
\hline Austin $^{42}$ & Self: Climate Protection Plan 2007 & $\begin{array}{l}\text { Rational: energy efficiency improvements } \\
\text { and demand-side management measures }\end{array}$ & Cost-effective demand-side management \\
\hline Berkeley $^{43}$ & $\begin{array}{l}\text { Introspective: Assembly Bill 32, The } \\
\text { Global Warming Solutions Act }\end{array}$ & Rational: reducing GHG emissions & $\begin{array}{l}\text { Policy tools to capture efficiency } \\
\text { improvements to existing building }\end{array}$ \\
\hline Berlin $^{44}$ & $\begin{array}{l}\text { Self: Energy Plan 1994: to reduce use } \\
\text { of energy, co-generation, energy } \\
\text { efficiency, use of renewable energy } \\
\text { in order to reduce GHG emissions }\end{array}$ & $\begin{array}{l}\text { Analytical: reducing per capita } \mathrm{GHG} \\
\text { emissions by } 25 \% \text { by } 2010\end{array}$ & $\begin{array}{l}\text { 'Public-private partnership' using energy } \\
\text { performance contracts to realize the } \\
\text { energy efficiency potential in } \\
\text { city-owned buildings }\end{array}$ \\
\hline $\operatorname{Riga}^{45}$ & - & $\begin{array}{l}\text { Absolute: efficient lighting initiative } \\
\text { (ELI) programme }\end{array}$ & $\begin{array}{l}\text { Renovation of public building lighting } \\
\text { system }\end{array}$ \\
\hline Stockholm $^{46}$ & $\begin{array}{l}\text { Introspective, self: European Union } \\
\text { ecodesign regulations }\end{array}$ & $\begin{array}{l}\text { Rational: reducing electricity consumption } \\
\text { from street lighting in the city which } \\
\text { accounted for } 60-80 \%\end{array}$ & $\begin{array}{l}\text { Changing to new lighting technologies, } \\
\text { particularly if these pose no risk of } \\
\text { compromising light quality }\end{array}$ \\
\hline Christchurch $^{47}$ & $\begin{array}{l}\text { Introspective: joint implementation } \\
\text { project (JI) under Kyoto Protocol and } \\
\text { 'projects to reduce emissions' (PRE) }\end{array}$ & Rational: reducing carbon emission & $\begin{array}{l}\text { Reducing carbon emission in public } \\
\text { buildings using renewable fuels/ } \\
\text { low-carbon emission fuels }\end{array}$ \\
\hline Dunedin ${ }^{48}$ & - & $\begin{array}{l}\text { Rational: access potential funding } \\
\text { from energy efficiency and conservation } \\
\text { authority (EECA) to help implement } \\
\text { the improvement projects }\end{array}$ & $\begin{array}{l}\text { Reduce-energy costs incurred in water } \\
\text { heating for a number of swimming } \\
\text { pools functioning under the city } \\
\text { council }\end{array}$ \\
\hline Gwalior $^{49}$ & Introspective: 'smart city Gwalior' & $\begin{array}{l}\text { Absolute: energy efficiency in the smart } \\
\text { city }\end{array}$ & Smart and energy-efficient lighting \\
\hline
\end{tabular}

performance with distance from ideal positive at 38.34 and from ideal negative at 0.00 . The distance from ideal positive and negative values was used to calculate performance score of each city (Figure 5).

Figure 5 shows that the average performance score of the cities is 0.36 and $66 \%$ of the cities fall below this score. Stockholm has the highest performance score at 0.88 and Austin has the least at 0 . Stockholm has energy savings and GHG emissions reduction at $90 \%$ and cost returns of $134 \%$, giving it the highest performance score. This city targeted operational energy sector by replacing 27,000 incandescent lamps with light-emitting diode (LED) traffic signals at 530 traffic control points. Austin shows energy savings and GHG emissions reduction at $1 \%$ and cost returns at $-66 \%$, giving it the lowest performance score. This city targeted operational energy sector by cost-effective demand-side management, which included rebates and incentives made available for businesses to improve efficiency of equipment that contributed to peaks in power demand. The reason for the poor performance of Austin can be attributed to the fact that it is a long-term strategy compared to the rest, and may take a longer time to achieve the desired results.

\section{Strategy formulation}

To determine the influence of strategy formulation process on the impacts achieved, the cities and their performance scores were compared with the type of awareness generated and approach adopted (Table 6).

Table 6 shows that the cities which had an introspective awareness towards the issue in hand have the highest consolidated performance score of 0.51 . The cities which had self-awareness towards the issue have a score of 0.45. Similarly, the cities which had incorporated an analytical approach for addressing the issue have the highest consolidated performance score at 0.47 , followed by those which adopted a rational approach having a score of 0.37 . The data indicate the significance of the strategy formulation process through the impacts achieved using them.

\section{Target energy type}

To assess if the energy efficiency strategies address the critical energy types, the strategies adopted by cities were classified into embodied, operational and transport 
RESEARCH ARTICLES

Table 5. Technique for order of preference by similarity to ideal solution analysis on case cities

\begin{tabular}{|c|c|c|c|c|c|c|c|c|}
\hline Strategy adopted & City & $\begin{array}{l}\text { Target energy } \\
\text { type* }\end{array}$ & $\begin{array}{c}\text { Energy } \\
\text { savings }(\%)\end{array}$ & $\begin{array}{l}\text { Emission } \\
\text { reduction }(\%)\end{array}$ & $\begin{array}{c}\text { Cost returns } \\
(\%)\end{array}$ & $\begin{array}{c}\text { Euclidean } \\
\text { distance }(+)\end{array}$ & $\begin{array}{c}\text { Euclidean } \\
\text { distance }(-)\end{array}$ & $\begin{array}{l}\text { Performance } \\
\text { score }(0-1)\end{array}$ \\
\hline $\begin{array}{l}\text { Light-emitting diode (LED) } \\
\text { traffic signals at } 107 \text { locations }\end{array}$ & Adelaide & 2 & 59 & 57 & -29 & 28.9 & 9.7 & 0.25 \\
\hline $\begin{array}{l}\text { A major library in the city was } \\
\text { retrofitted to replace } \\
\text { inefficient low-voltage } \\
\text { down-lights and the } \\
\text { air-conditioning control } \\
\text { system }\end{array}$ & Sydney & 2 & 46 & 46 & 89 & 23.7 & 16.3 & 0.41 \\
\hline $\begin{array}{l}\text { Replacing } 720 \text { lamps that were } \\
\text { quite old. The measures } \\
\text { consist of lamp reconstruction, } \\
\text { lamp change and installation } \\
\text { of control systems }\end{array}$ & Graz & 2 & 56 & 56 & -60 & 32.2 & 8.1 & 0.20 \\
\hline $\begin{array}{l}\text { Energy conservation ordinance } \\
\text { applies to residences at the } \\
\text { time of sale or lease }\end{array}$ & Berkeley & 2 & 15 & 15 & 63 & 30.5 & 10.4 & 0.25 \\
\hline $\begin{array}{l}\text { School buildings offered by } \\
\text { tender for energy performance } \\
\text { contracts }\end{array}$ & Berlin & 1 & 20 & 20 & 117 & 25.1 & 22.6 & 0.47 \\
\hline $\begin{array}{l}\text { Renovated indoor lighting of } \\
\text { sports education academy }\end{array}$ & Riga & 2 & 48 & 48 & 11 & 29.7 & 8.1 & 0.21 \\
\hline $\begin{array}{l}\text { LED traffic signals installed to } \\
\text { replace } 27,000 \text { lamps at } 530 \\
\text { traffic control points }\end{array}$ & Stockholm & 2 & 90 & 90 & 134 & 4.9 & 34.7 & 0.88 \\
\hline $\begin{array}{l}\text { Heat-pump installation at a } \\
\text { public swimming pool was } \\
\text { matched to the waste heat } \\
\text { stream to extract and return } \\
\text { energy to the pool }\end{array}$ & Dunedin & 2 & 39 & 31 & 54 & 29.3 & 9.7 & 0.25 \\
\hline $\begin{array}{l}\text { Energy-efficient street lighting } \\
\text { in the city }\end{array}$ & Gwalior & 2 & 25 & 25 & 65 & 29.5 & 10.9 & 0.27 \\
\hline
\end{tabular}

*Note: (i) Embodied energy, (ii) Operational energy and (iii) Transport energy.

energy. Figure 6 shows the percentage of cities targeting each energy type.

Figure 6 shows that 10 cities (91\%) target operational energy, one city $(9 \%)$ targets embodied energy and no cities targets transport energy. The data were compared with the global and urban energy consumption patterns shown in Figure 3.

Nine per cent of the strategies are targeting embodied energy, which constitutes $28 \%$ of the total energy consumed at both urban and global levels. Also, 91\% of the strategies adopted by cities address operational energy which constitutes $46 \%$ at the global level and $41 \%$ at the urban level. None of the cities addresses transport energy which constitutes $26 \%$ of energy consumed at the global level and $31 \%$ at the urban level, which was unexpected since the literature review showed that the past studies on energy consumption mainly focused on the transport sector.

The data illustrates that the most critical energy types consumed by cities and targeted energy types in the strategies formulated show a disparity between them.

\section{Limitations of the study}

The case-study cities were taken from the IEA report on best practices ${ }^{18}$ and hence no other specific criteria like 
Stat $\bigotimes$ Euclidean_distance_negative Euclidean_distance_positive

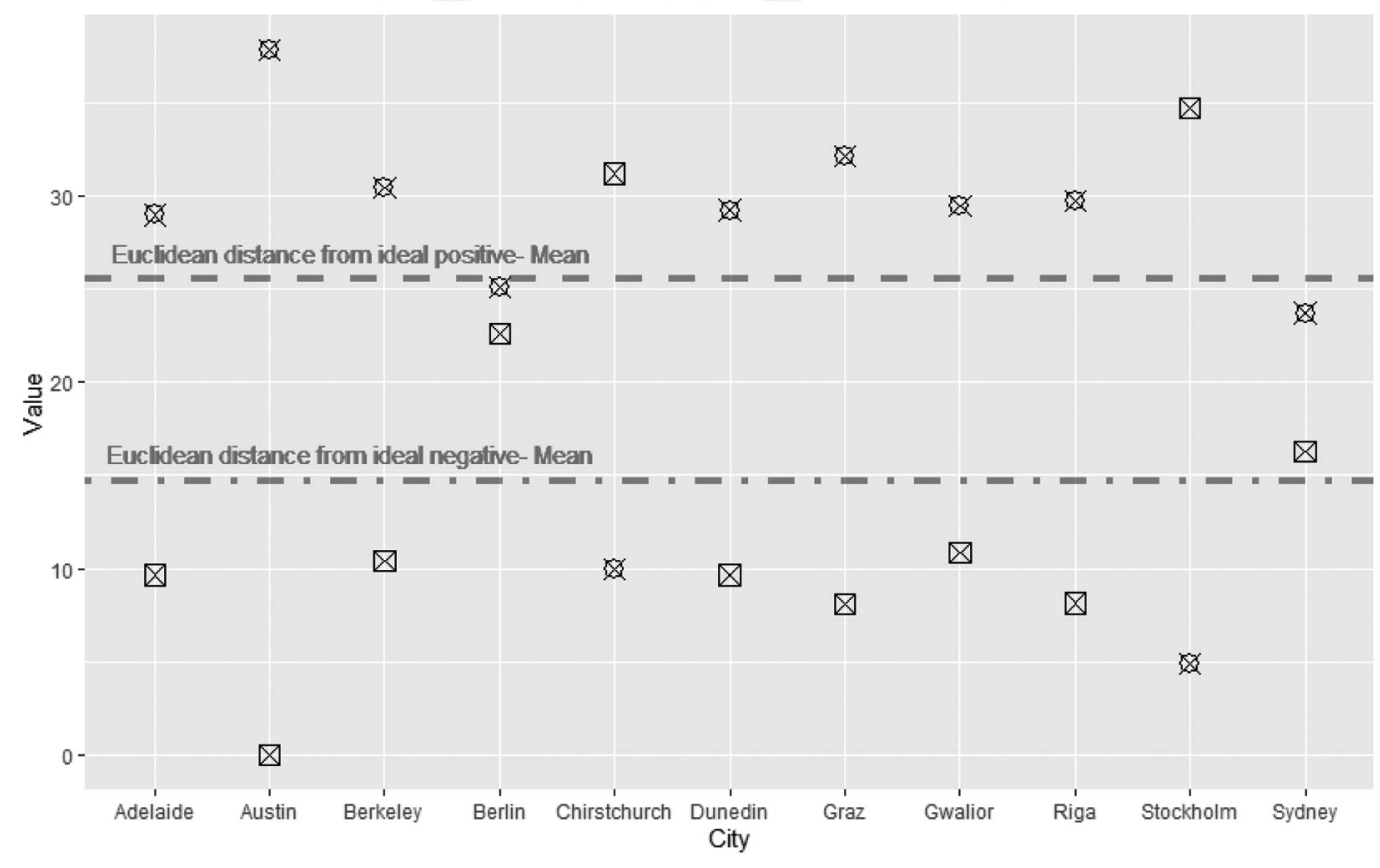

Figure 4. Euclidean distance from ideal positive and ideal negative scenarios calculated through technique for order of preference by similarity to ideal solution (TOPSIS) analysis.

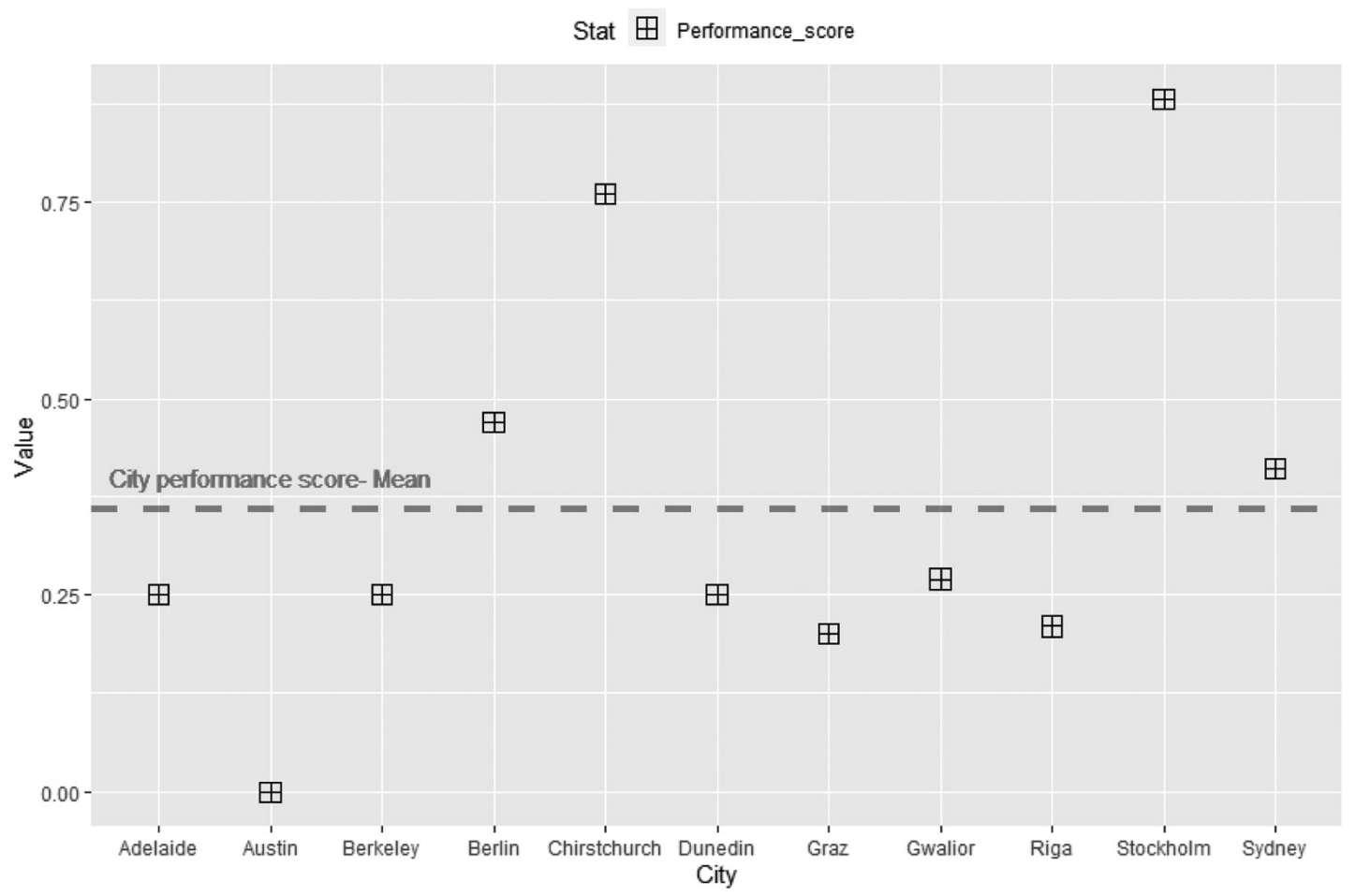

Figure 5. Performance score of cities according to TOPSIS analysis.

climate and socio-economic status of the city were considered in the selection process. For the same reason, the strategies were assessed based on a set of universal crite- ria, namely target energy type against critical energy type, process of strategy formulation and impacts achieved based on the most widely used parameters in 
$\mathrm{M} \& \mathrm{~V}$ tools. Hence the study has not taken into account the specific set of conditions pertaining to each city and the strategy adopted.

\section{Discussion}

It is well established from the above discussions that cities are the prime consumers of global energy and are responsible for a significant share of global GHG emissions. Since cities pose the greatest threats, the greatest opportunities also lie within them. Energy-efficient cities hold a tremendous potential and will be a critical aspect for sustainable development in the future ${ }^{27}$.

In order to plan for energy efficient cities, a critical appraisal of the current practices in energy-efficient cities has been conducted. Eleven energy efficiency strategies adopted by cities, which are cited as best practices, were assessed based on impacts achieved, strategy formulation process and target energy type.

Addressing the energy sector in a city is complex due to the multiple factors which influence their utilization, quantity and quality. Energy efficiency in cities constitutes a strategic development vector in rapid evolution, with multi-dimensional sectors as its target, namely population behaviour, transportation, industry, agriculture, buildings and construction sector ${ }^{28}$. Most cities tend to

Table 6. City performance score based on type of awareness and approach adopted

\begin{tabular}{lcc}
\hline & Performance score & No. of cities \\
\hline Awareness about the issue & 0.25 & \\
Inferential & 0.45 & 2 \\
Self & 0.51 & 5 \\
Introspective & & \\
Approach adopted & - & 0 \\
Positive & - & 0 \\
Creative & 0.24 & 2 \\
Absolute & 0.37 & 8 \\
Rational & - & 0 \\
Logical & 0.47 & 1 \\
Analytical & & \\
\hline
\end{tabular}

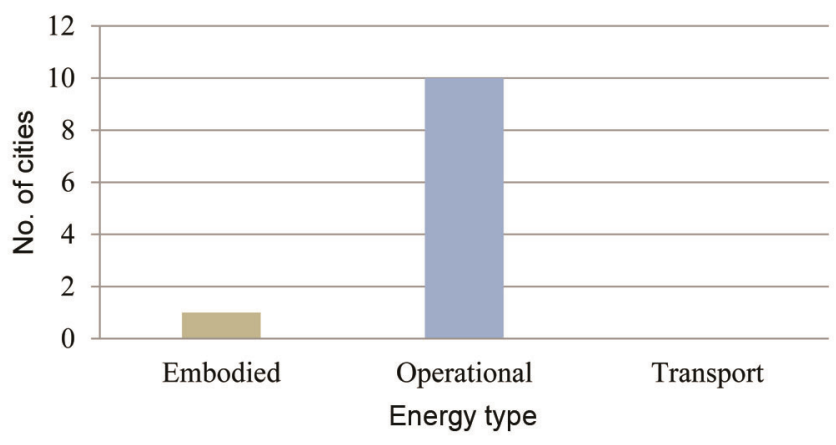

Figure 6. Target energy sector for selected cities. have buildings, transport and municipal services strongly influencing their energy consumption; however, cities where industries account for a major share of energy consumption exist in countries like China and India.

The World Bank mentions that in order for cities to take concrete actions to improve energy efficiency, it is essential to understand what, where and how big their energy-savings opportunities are, what measures are needed to capture the savings and at what costs, what the implementation constraints are, and how priorities should be set for a given local capacity and resources ${ }^{20}$. To cite an example, in the Indian state of Uttarakhand in Northwestern Himalaya, the resident population faced difficulties due to lack of access to any energy sources. The area also faced threats due to forest fires in the pine forest which was spread in about 3.43 lakh ha, and shed 20.58 lakh tonnes of dry biomass every year. Non-governmental organizations (NGOs) and authorities adopted power generation through biomass gasification technology which successfully provided electricity in the region, and biomass residue delivered as cooking fuel which resulted in the reduction of trees being cut down in the forests. This also offered job opportunities to the residents and reduced forest fires and associated GHG emissions ${ }^{29}$. The project gained the attention of Government authorities and was further assessed for identifying possible barriers in strengthening and adopting the technology to more $\operatorname{areas}^{30}$.

Comprehensive assessment of energy performances in cities is an essential starting point to facilitate enhanced energy efficiency in cities ${ }^{28}$. Formulating energy efficiency strategies for a city requires detailed assessment of the different factors which influence their use in the city. For instance, city energy performance assessment models like SDEWES $^{10}$, TRACE $^{31}$, CASBEE $^{32}$, ENVI-met $^{33}$, GIS $^{34}$, etc. are used in various countries to assess the performance of cities, regions and districts with regard to energy efficiency and sustainability. They are used in assessing energy performance, calculate the associated GHG emissions, developing future scenarios, identifying critical areas, formulating strategies and estimating the costs incurred for a given set of conditions which exists in a city. These methods have been practised in developed countries since the last few decades and are now being adopted by developing countries as well ${ }^{35}$.

\section{India's initiatives towards energy-efficient cities}

Comprehensive energy performance assessment of cities has not been practised in India yet. The Government of India has adopted various nationwide policies from the 'The Energy Conservation Act' of 2001 to 'Draft National Cooling Action Plan' of 2018, that focus on specific target sectors like buildings (ECBC, BEE), vehicles (Smart and Low Carbon Mobility), smart services (Smart City 
Mission), energy-efficient appliances (Street Lighting National Programme), etc. A major shortfall of these policies is that, regardless of any energy and cost savings achieved, they do not explore the local issues, potentials, opportunities and constraints. In other words, a comprehensive assessment and understanding of the context is missing. To quote an example from the Akola Municipal Corporation, the city replaced 11,500 of its street lights with energy-efficient ones as a part of its energy-efficient street lighting project ${ }^{36}$. This inspired other authorities to undertake similar initiatives in Bhubaneswar, Jaipur, Visakhapatnam and Puducherry ${ }^{37}$. The replication of interventions raises the question whether five cities of different magnitude, socio-economic profile, geographic and climatic conditions should be addressing energy efficiency in the same manner.

The Uttarakhand example mentioned earlier illustrates a situation where the local issues and opportunities were scientifically assessed, which provided guidance in developing policies that could deliver multiple social, economic and environmental benefits to the community.

The main takeaways from this study are as follows: the significance of the type of awareness generated and approach adopted in formulating energy efficiency strategies in cities, and for achieving desirable beneficial impacts. Cities with self-awareness about an issue they are facing, and undertaking an analytical approach to solve them have an elevated performance in comparison to other cities due to the inherent awareness of the context involved.

As suggested by Geddes ${ }^{38}$, context study at the municipal and regional levels is a prerequisite before formalizing energy efficiency strategies in cities. Identifying the critical energy types and associated issues through a comprehensive study of the city, understanding the local potentials, opportunities and constraints will yield better results than when blindly adopting global and national initiatives.

The current practices in the Indian context reveal the lack of comprehensive studies at city level; and how cities are merely adopting successful examples from elsewhere without assessing the local context.

The situation also raises a question of whether focusing on smart infrastructure and energy-rated appliances for all cities is the right approach for India. Strategies like these which have delivered exceptional results in developed nations were achieved where the residents had the awareness, knowledge, wealth and willingness to adapt and change their lifestyle for a better future. Adopting the same approach and expecting this to work in a country with a far more complex socio-economic strata and exaggerated wealth inequalities seems far-fetched, if not unattainable. The day-to-day struggles of the common man, in addition to the environmental threats pose a peculiar problem in itself when it comes to India. Hence we require a more sensitive and innovative approach to deal with such problems. These strategies can be expected to deliver only short-term benefits.

The present study also indicates the need for an energy balance model/equation which will manifest the gravity of all the factors which play a role in energy consumption. Future research will be directed towards identifying these indicators for urban areas. The indicators will then be used for assessing cities in various climatic and geographic regions to establish a correlation between them and energy consumption.

\section{Conclusion}

The impact assessment on case cities done using TOPSIS analysis revealed an overall poor performance. This result can be attributed to the process of strategy formulation adopted by cities towards the issues they face. Only $18 \%$ of the cities have identified their issue through selfawareness and $73 \%$ have adopted a rational approach towards the issue. This indicates that most of the cities have adopted an agenda framed by a higher authority towards an issue, without assessing their local context.

The target sector assessment of cities indicates that there is a discrepancy between the critical energy types and the target energy types, in the strategies formalized. The current strategies for developing energy efficient cities in the Indian context need a revamp in their approach; wherein the individuality of problems must be understood to tailor strategies and tactics at the city level. Future policies may call for extra attention towards investment in research and development, sensitizing people and generating awareness prior to developing 'smart cities'.

1. International Energy Agency, India Energy Outlook 2015 Paris, 2015.

2. Nations, U., Transforming our World: The 2030 Agenda for Sustainable Development. United Nations, 2015.

3. Bose, R. K., Energy efficient cities: assessment tools and benchmarking practices. The World Bank, Washington, 2010.

4. Banister, D., Watson, S. and Wood, C., Sustainable cities: transport, energy, and urban form. Environ. Plant B, 1997, 24, 125143.

5. Gilbert, G. and Dajani, J. S., Energy, urban form and transportation policy. Transp. Res., 1974, 8, 267-276.

6. Long, Y., Mao, Q. and Shen, Z., Urban form, transportation energy consumption, and environment impact integrated simulation: a multi-agent model. In Spatial Planning and Sustainable Development, Springer, The Netherlands, 2013, pp. 227-247.

7. Kimball, M., Chester, M., Gino, C. and Reyna, J., Assessing the potential for reducing life-cycle environmental impacts through transit-oriented development infill along existing light rail in Phoenix. J. Plant Educ. Res., 2013, 33, 395-410.

8. Shim, G.-E., Rhee, S.-M., Ahn, K.-H. and Chung, S.-B., The relationship between the characteristics of transportation energy consumption and urban form. Ann. Reg. Sci., 2006, 40, 351-367.

9. Nichols, B. G. and Kockelman, K. M., Urban form and life-cycle energy consumption: case studies at the city scale. J. Transp. Land Use, 2015, 8, 115-128. 
10. Kılkış, Ş., Benchmarking south east European cities with the sustainable development of energy, water and environment systems index. J. Sustain. Dev. Energy, Water Environ. Syst., 2018, 6, 162-209.

11. IEA Market Report Series, Energy Efficiency 2018: Analysis and outlooks to 2040, Paris, 2018.

12. Arup, W. E. C., Perspective input into the World Energy Council Scenarios: 'Innovating Urban Energy', London, 2016.

13. Frijns, J., Middleton, R., Uijterlinde, C. and Wheale, G., Energy efficiency in the European water industry: learning from best practices. J. Water Climate Change, 2012, 3, 11-17.

14. Crawford, G. and Sandino, J., Energy efficiency in wastewater treatment in North America: a compendium of best practices and case studies of novel approaches, Report, Water Environment Research Foundation, Alexandria, 2010.

15. Nazir, C. P., Coastal power plant: a hybrid solar-hydro renewable energy technology. Clean Energy, 2018, 2, 102-111.

16. Troy, P., Holloway, D., Pullen, S. and Bunker, R., Embodied and operational energy consumption in the city. Urban Policy Res., 2003, 21, 9-44.

17. Doherty, M. et al., Relationships between form, morphology, density and energy in urban environments. GEA Backgr. Pap., 2009, no. 28.

18. Jollands, N., Kenihan, S. and Wescott, W., Promoting energy efficiency: best practices in cities. Paris International Energy Agency, Canberra, 2008.

19. Khatib, J., Sustainability of Construction Materials, Woodhead Publishing, 2016.

20. World Bank, E., Energy Efficient Cities. Energy Sector Management Assistance Program, 2014.

21. Program, E. S. M. A., Assessing and Measuring the Performance of Energy Efficiency Projects, World Bank, Washington, 2017.

22. Jahanshahloo, G. R., Lotfi, F. H. and Izadikhah, M., Extension of the TOPSIS method for decision-making problems with fuzzy data. Appl. Math. Comput., 2006, 181, 1544-1551.

23. Audi, R., Epistemology: A Contemporary Introduction to the Theory of Knowledge, Routledge, 2010

24. Myers, G. E., Introspection and self-knowledge. Am. Philos. $Q$, 1986, 23, 199-207.

25. Sadegh-Zadeh, K. et al., Handbook of Analytic Philosophy of Medicine, 2012.

26. Woods, L., 6 Approaches to Problem Solving- How Does Your Mind Work? Manag. Am., 2017.

27. Brundtland, G. H., Khalid, M., Agnelli, S., Al-Athel, S., and Chidzero, B., Our common future, Report, Oxford University Press., Oxford, United Kingdom, 1987.

28. Poggi, F., Firmino, A. and Amado, M., Assessing energy performances: a step toward energy efficiency at the municipal level. Sustain. Cities Soc., 2017, 33, 57-69.

29. Government of India, V., Electricity generation using pine needles in Uttarakhand. Energy Best Pract., 2016.

30. Sengar, A. et al., Prioritization of barriers to energy generation using pine needles to mitigate climate change: evidence from India. J. Clean. Prod., 2020, 275, 123840.

31. ESMAP, Tool for Rapid Assessment of City Energy (TRACE 2.0). A Manual for Experts and City Officials, The World Bank, Washington, 2018.
32. Berardi, U., Sustainability assessment of urban communities through rating systems. Environ. Dev. Sustain., 2013, 15, 15731591.

33. Yang, X., Zhao, L., Bruse, M. and Meng, Q., An integrated simulation method for building energy performance assessment in urban environments. Energy Build., 2012, 54, 243-251.

34. Ascione, F., De Masi, R. F., de Rossi, F., Fistola, R., Sasso, M. and Vanoli, G. P., Analysis and diagnosis of the energy performance of buildings and districts: methodology, validation and development of urban energy maps. Cities, 2013, 35, 270-283.

35. World Bank, E., Annual Report 2017 Washington, 2017.

36. World Bank, E., Good practices in city energy efficiency: Akola Municipal Corporation, India - Performance Contracting for Street Lighting Energy Efficiency Washington, 2009.

37. Sarkar, A., Singh, S. K. and Neelima Jain, V. D., India - energyefficient street lighting: implementation and financing solutions, Washington, 2015.

38. Geddes, P., Cities in Evolution: an Introduction to the Town Planning Movement and to the Study of Civics, Williams, London, UK, 1915.

39. Ratings, E., Street and public lighting, 2014.

40. Patrick, X. W. and Zou, R. S., Sustainable Built Environment National Research Center, 2017.

41. Markus Radocha, B. B., ELTIS: The Urban Mobility Observatory.

42. Council, A. C., Sustainability Resolution, 2007.

43. Elkind, E. N., Saving energy: how California can launch a statewide retrofit program for existing residences and small businesses, 2011.

44. Secretariat, E. C., Third party financing: achieving its potential, 2003.

45. Commission, U. of the B. C. S. C., UBC Wheel, Good Practice Database, 2009

46. Jägerbrand, A., LED (light-emitting diode) road lighting in practice: an evaluation of compliance with regulations and improvements for further energy savings. Energies, 2016, 9, 357.

47. Manatū Mō Te Taiao, M. for the E., United Nations Framework Convention on Climate Change, 2007.

48. Energy Management Association of New Zealand.

49. Ministry of Housing, Government of India, Smart Cities Mission, 2017.

ACKNOWLEDGEMENTS. We thank Ms Nilanjana Dasgupta Sur (Assistant Professor, Urban Planning Department, School of Planning and Architecture, New Delhi) for guidance during the initial stages of the study, and Ms Ranjini Mukherjee (Disaster Risk Reduction Specialist, United Nations Resident Coordinator's Office), Ms Aparna Soni (Assistant Professor, Department of Urban and Regional Planning, School of Planning and Architecture, Bhopal), Mr Jagdeep Kapoor (Associate Town and Country Planner, UIDSSMT Division) for their valuable inputs. We also thank Ms Nony Gupta (Urban Planner, IPE Global Limited) for the assistance she provided.

Received 18 November 2020; revised accepted 9 April 2021

doi: $10.18520 / \mathrm{cs} / \mathrm{v} 121 / \mathrm{i} 3 / 372-383$ 